reappeared. We are paying insufficient attention to this probable global event. We have limited understanding of the molecular events that underlie pandemics of influenza: to have any hope of preventing one of these outbreaks we need to identify the specific interplay among people, pigs, and birds that spawns a new pandemic virus. Current preventive strategies involving vaccines and antiviral drugs could be expected to blunt the pandemic in only a few regions of the world. Inactivated and live attenuated vaccines for influenza are about equally efficacious $(60-90 \%)$ when antigenically matched vaccines are used. ${ }^{6}$

Reverse genetics offers a new strategy for improving influenza vaccines-namely, inserting defined mutations into attenuated vaccines or increasing the yields of virus for inactivated vaccines. ${ }^{7}$ But this strategy could not be expected to overcome the initial lag time in the preparation of a matched vaccine. Although antiviral drugs such as amantadine and its analogue rimantadine would probably be efficacious in the first wave of infection, drug resistance would emerge rapidly, making control of the pandemic unlikely. A new group of antiviral drugs, designed around the structure of the sialic acid binding site on the neuraminidase molecule, have shown promise in animal model studies and are now being tested clinically. ${ }^{8}$ These first generation antiviral drugs based on structure will probably also have limitations, but they herald future strategies that may provide some control of new pandemics. In the meantime, we need to plan for the next pandemic.

ROBERT G WEBSTER

Department of Virology/Molecular Biology, Rose Marie Thomas professor

St Jude Children's Research Hospital,

Memphis, TN 38101,

USA

1 Webster RG, Bean WJ, Gorman OT, Chambers TM, Kawaoka Y. Evolution and ecology of influenza A viruses. Microbiol Rev 1992;56:152-79.

2 Shortridge KF, Stuart-Harris CH. An influenza epicentre? Lancet 1982;ii:812-3.

Scholtissek C, Schultz U, Ludwig S, Fitch WM. The role of swine in the origin of pandemic influenza. In: Hannoun C, Kendal AP, Klenk HD, Ruben FL, eds. Options for the control of influenza II. Amsterdam: Elsevier Science Publishers, 1993:193-201.

4 Castrucci MR, Donatelli I, Sidoli L, Barigazzi G. Kawaoka Y, Webster RG. Genetic reassortment between avian and human influenza A viruses in Italian pigs. Virology 1993;193:503-6.

5 Claas ECJ, Kawaoka Y, de Jong JC, Masurel N, Webster RG. Infection of children with avianhuman reassortant influenza virus from pigs in Europe. Virology (in press).

6 Edwards KM, Dupont WD, Westrich MK, Plummer WD Jr, Palmer PS, Wright PF. A randomized controlled trial of cold-adapted and inactivated vaccines for the prevention of influenza A viruses. F Infect $D$ is 1994;169:68-76.

7 Enami M, Luytjes W, Krystal M, Palese P. Introduction of site-specific mutations into the genome of influenza virus. Proc Natl Acad Sci USA 1990;87:3802-5.

8 Von Itzstein M, Wu W-Y, Kok GB, Pegg MS, Dyason JC, Jin B, et al. Rational design of potent sialidase-based inhibitors of influenza virus replication. Nature 1993;363:418-23.

\title{
The referral system
}

\section{Prevents overmedicalisation and keeps costs down}

The implementation of the British National Health Service in 1948 as a system based on generalists, with general practitioners as the gatekeepers to secondary care, institutionalised the separation of primary and secondary care. Since then it has proved a cost effective model, 12 emulated by several health maintenance organisations in the United States in an attempt to contain costs. ${ }^{3}$ Now, however, the internal market is raising questions about the separation of primary and secondary care and may undermine a key component-the referral of a patient by a general practitioner for advice on diagnosis or management by a specialist.

Two elements of the reforms in particular are changing the relation between primary and secondary care. Firstly, the shift of emphasis from secondary to primary care has altered the historical imbalance in the relationship between general practitioners and specialists. Primary care now has a pivotal role in the NHS, and the new commissioning arrangements give general practitioners the power to plan and manage more directly their patients' care. Contracting encourages interaction between general practitioners and hospitals, which, at best, can lead to more cooperation and a more responsive service from the specialists to whom general practitioners refer their patients.

Secondly, there is an increasing emphasis on care in the community, with fewer inpatient admissions, shorter inpatient stays, more day case surgery, and a policy of encouraging long stay patients to leave institutional care and live in the community. Some specialists now consider at least part of their work to be outside hospital, in outreach clinics in the community. ${ }^{45}$ This has sometimes happened in response to general practitioners' requests and has made the referral process more convenient for patients. But a danger exists that the growth of outreach clinics may gradually but inexorably provide open access to patients without the need for referral. What are the dangers in such a development?
The key role of the general practitioner is as the interpreter of the interface between illness and disease. According to Kleinman, "Illness complaints are what patients and their families bring to the practitioner . . . disease, however, is what the practitioner creates in the recasting of illness in terms of disorder. Disease is what practitioners have been trained to see through the theoretical lenses of their particular form of practice."6 General practitioners accept the responsibility for making an initial decision on every problem with which a patient presents, and $90 \%$ of problems are dealt with entirely within general practice. ${ }^{78}$ An awareness of the psychological and social factors in a presentation combines with history taking and clinical examination to produce a diagnosis and a management plan. ${ }^{9}$ Part of that plan is to help the patient interpret and cope with illness ${ }^{10}$ and to refer to specialists when appropriate. This role is crucial and will be lost if the referral system is bypassed.

Routine open access to specialist clinics would inevitably lead to fragmentation of patients' care and undermine the unique role of the general practitioner as a generalist. It would also increase the likelihood of overinvestigation of patients with psychosomatic illness and of Balint's "collusion of anonymity," in which many specialists see a patient but no one accepts overall responsibility. ${ }^{11}$

The referral system enables a patient to have at least two opinions: the view of a specialist about a specific disease and the view of the general practitioner who knows the patient and family ${ }^{12}$ and the context of the patient's problem. ${ }^{13}$ Self referrals to specialists often generate follow up appointments to review progress-these are more appropriately the responsibility of the general practitioner. Specialists also tend to refer to other specialists rather than the general practitioner when they encounter problems outside their sphere of competence, many of which could be managed by the general practitioner.

If fragmentation of a patient's care is to be avoided the 
general practitioner must remain the focus of referral from primary to secondary care. People are vulnerable when ill and may not have enough information to select the most appropriate service. Moreover, some patients present with non-specific symptoms, such as tiredness, in which case the right specialist is not obvious. Here, above all, they need the diagnostic skills of a generalist. Furthermore, if specialists were to be confronted with the complex of organic and functional disease that is characteristic of many presentations in general practice their specialist knowledge might be diluted. The erosion of the referral system would be likely to slow the development of specialist medicine and make it less effective, efficient, and innovative. ${ }^{14}$

There are other strengths of the gatekeeper system that would be lost should self referral become widespread. Self referral would undermine the general practitioner's responsibility to unravel the patient's symptoms, which are often non-specific and disorganised, and to help the patient choose discriminately when specialist advice is needed. The single comprehensive lifelong record of a patient's health and care would also cease to exist. This record is kept and collated by the general practitioner, is passed to successive general practitioners, and is indispensable for long term medical management.
In short, therefore, the referral system contributes to high standards of care by limiting overmedicalisation, by permitting an efficient division of tasks between generalists and specialists, by freeing specialists to develop their special knowledge, and by containing the cost of medical care.

BRENDAN SWEENEY

General practitioner

The Crescent Medical Practice,

Glasgow G51 1AT

1 Sjonell G. Effect of establishing a primary health care centre on the utilisation of primary health care and other out-patient care in a Swedish urban area. Fam Pract 1986;3:148-54

Welch W, Miller ME, Welch HG, Fisher ES, Wennberg JE. Geographic variation in expenditures for physicians' services in United States. $N$ Engl f Med 1993;328:621- 7.

3 Fry J, Horder JP. Primary care in twelve countries: a comparison. London: Nuffield Provincial Hospitals Trust, 1994

4 Morris J. The case for the community geriatrician. BMF 1994;308:1184.

5 Bailey J, Black $M$, Wilkin W. Specialist outreach clinics in general practice. BMF 1994;308:1083.

6 Kleinman A. The illness narratives, suffering, healing and human condition. New York: Harper Collins, 1988:5.

7 Horder J, Horder E. Illness in general practice. Practitioner 1954;173:177-89.

8 General Household Survey 1989. London: OPCS, 1991. (Series GHS No 20.)

9 Horder J, Harris C, Byrne P, Freeling P, Irvine D, Marinker M, et al. The educational needs of the future general practitioner. $\mathcal{F} R$ Coll Gen Pract 1969;18:358- 60.

10 Charlton BG. Holistic medicine or the humane doctor. Brf Gen Pract 1993;43:475-7.

11 Balint M. The doctor: his parient and the illness. London: Churchill Livingstone, 1957:69-80.

12 Huygen FJA. Family medicine. The medical life history of families. London: Royal College of General Practitioners, 1990.

13 Howie JGR, Bigg AR. Family trends in psychotropic and antibiotic prescribing in general practice. $B M \mathcal{F}$ 1980;280:836.

14 Royal College of General Practitioners. Evidence to the monopolies and mergers commission inquiry into private medical services. London: Royal College of General Practitioners, 1993.

\section{Switching devices and independence of disabled people}

\section{Their prescription should be better integrated with broader assessments of disability}

An environmental control system is a switching device that allows a disabled person to control many aspects of his or her home environment from a single unit, and the prescription of one may allow people with severe physical disabilities to continue to be independent and to live at home. The most common equipment that can be controlled is a door intercom, telephone, lighting, and domestic appliances such as television, radio, and video recorder. The system can be operated in various ways, from simple hand or foot switches to more complex chin controls, suck-puff controls, and even controls governed by eye movements. Environmental controls can have a major impact on the lives of severely disabled people, not only by enhancing their independence but also by reducing the stress and workload on their carers.

This equipment is currently supplied on prescription, from the Department of Health's central funds, after a nominated environmental control assessor has granted approval according to written criteria for eligibility, 12 but two recent reports have criticised this system. ${ }^{34}$ In particular the report of a working party of the British Society of Rehabilitation Medicine highlights several deficiencies. The environmental control assessor often receives no training and does not always have expert knowledge in physical disability. The assessment process tends to be carried out in isolation from a broader assessment of the needs of the disabled person. For example, around $40 \%$ of users of environmental control systems are without speech, yet the disabled person is not assessed for a communication aid at the same time-or, sometimes, at all. Health professionals generally are ignorant about the availability and scope of environmental control equipment. Consequently, many potential users never get referred: around $2 \%$ of the adult population in Britain has a severe dis- ability but only around 3000 use a system. The needs of disabled people change over time, yet there is no system of clinical follow up after the initial prescription.

Clearly the present system needs an overhaul. The Department of Health is in the process of making two important changes. Firstly, new contracts have recently been let that enable the prescription of more modern systems, using radio frequency and infrared technology. These new systems have small, internally powered selection units, which can be mounted on a wheelchair. The systems are modular, and this should facilitate better integration with other technological advances in robotics, computers, communication aids, and "smart house" technology.

Secondly, the budget for environmental controls is to be devolved from central funds to the new regional offices with effect from next April. The budgets will probably then pass further down to district purchasing level. Decentralisation should promote better integration with local rehabilitation services, but it is important to guard against these budgets being reduced or lost altogether if districts give environmental controls low priority. This would have a serious effect on severely disabled people, who are already disadvantaged when it comes to expressing their opinions.

The report of the British Society of Rehabilitation Medicine makes several recommendations. There should be a lead provider with whom the purchasers contract for the overall delivery and coordination of the service for a population of around three million people. The central coordinating role should include not only organisation of the service and budgetary management but also training and education of staff, review and follow up arrangements, and a system for audit and quality assurance. The central 